\title{
Smoking increases the premature associated senescence phenotype of circulating Endothelial Progenitor Cells
}

\author{
Kumboyono Kumboyono, ${ }^{1, *}$, Wiwit Nurwidyaningtyas ${ }^{2}$, Indah Nur Chomsy ${ }^{2}$, Fibe \\ Yulinda Cesa ${ }^{3}$ and Titin Andri Wihastuti ${ }^{4}$ \\ ${ }^{1}$ School of Nursing, Faculty of Medicine, University of Brawijaya, Malang, Indonesia; ${ }^{2}$ Doctoral Program of Medical Science, Faculty of \\ Medicine, University of Brawijaya, Malang, Indonesia; ${ }^{3}$ Master Program of Biomedical Science, Faculty of Medicine, University of \\ Brawijaya, Malang $;^{4}$ Department of Basic Nursing Science, Faculty of Medicine, University of Braijaya, Malang
}

Received: August 17, 2020; Revised: November 26, 2020; Accepted: December 21, 2020

\begin{abstract}
Smoking is a risk factor for cardiovascular disease. Notably, it is associated with endothelial progenitor cells (EPCs) dysfunction. It also influences the shift of the EPCs mobilisation from bone marrow. We hypothesized that smoking could induce a premature associated senescence phenotype on the circulating population of EPCs, which may contribute to the default of recovery endothelial injury. Peripheral Blood Mononuclear Cell (PBMC) samples were collected from 30 smokers at least for five years and 31 healthy subjects (non-smoker) as control. CD $117^{+}$and CD133 ${ }^{+}$cells were confirmed as the population of endothelial progenitor cells. Those marked cells with SA- $\beta$ galactosidase were quantified as senescence phenotype. Then, FACS assessed the targeted cells. The average concentration of CD133 ${ }^{+} / \mathrm{CD} 117^{+}$was $0.05 \%( \pm 0.03)$ for smoker subjects and $0.03 \%( \pm 0.02)$ for non-smoker $(p<0.05)$. Almost all of the EPCs population $(98.33 \pm 3.53 \%)$ in the smoker group expressed SA- $\beta$ gal positive cells $(\mathrm{p}<0.001)$. Thus, this study suggests that smoking is associated with a significant elevated premature senescence of EPCs, which may contribute to diminished bioavailability of mature EPCs of the smoker, reducing the potency of vascular maintenance and repair.
\end{abstract}

Keywords: premature senescence, endothelial progenitor cells, smoking, vascular repair

\section{Introduction}

Endothelial progenitor cells (EPCs) effluxed from bone marrow (BM) in response to various molecular signalling pathways. The EPCs population is around 0.0001 in the blood circulation (Tagawa et al., 2015; Zhao et al., 2016). EPCs are required for the repair of the endothelium when endothelial injury or dysfunction. Regenerative potential to repair endothelial injury is carried out only by mature EPCs. Mobilization of population endothelial progenitor cells from $\mathrm{BM}$ is the initial stage of maturation or differentiation of various cell types, including EPCs (Hur et al., 2004; Zhang et al., 2014; Tagawa et al., 2015; Zhao et al., 2016). Hematopoietic progenitor cells are characterized by CD117 and CD133 surface markers (Hur et al., 2004; Gargett et al., 2009). Changes in the number of hematopoietic progenitor cells in the blood circulation affect the availability of mature EPCs. Various factors that modulate endothelial dysfunction also induce dysfunction of EPCs and induce the reduction in circulating EPCs (Hur et al., 2004; Zhang et al., 2014; Tagawa et al., 2015; Zhao et al., 2016).

The senescence of the human cell is considered an essential hallmark of the ageing process (Honn et al., 2017). Ageing is a complex phenomenon associated with increasing age or the accumulation of long-term oxidative stress exposure. Cells characterised as senescence are recognised viable, but they cannot perform a functional role due to cell cycle arrest for a certain period; meanwhile, the disrupted factor exposure remains constant. Senescence markers were identified as intracellular specific changes, such as increased senescence-associated $\beta$-galactosidase activity (SA- $\beta$-Gal). The SA- $\beta$-ga is a marker widely used to identify senescence in cells and tissues (Young et al., 2009; Kurz et al., 2000; Lee et al., 2006).

Smoking is an established risk factor for cardiovascular disease (CVD) (Kaplan et al., 2017). Tobacco smoke contains more than 4720 compounds, including wellknown harmful chemicals such as polycyclic aromatic hydrocarbons, free radicals, and oxidative gases (Yao et al., 2008; Rafacho et al., 2011). Smoking might become a habit due to the addictive property of nicotine (Kumboyono et al., 2020). Nicotine induces the mesenchymal (MSC) biological function because of its underlying cause of various diseases. But, researchers have argued this phenomenon due to the limited study (Huertas et al., 2010; Kumboyono et al., 2020). Several studies claim that smoking significantly inhibits the regenerative potential of MSC and has been implicated in the early degeneration of mesenchymal tissue (Greenberg et al., 2017). This study investigates the effect of smoking exposure on EPC's biological changes in vivo, further exploring the consequence of smoking-mediated premature senescence in the EPCs population.

\footnotetext{
* Corresponding author. e-mail: publikasikoe@gmail.com.
} 


\section{Methods}

\subsection{Research design}

The study was a cross-sectional study with a simple random sampling technique-informed consent was given to collect peripheral blood from each participant. Participants were divided into two groups; current smokers are participants who smoked $>10$ cigarettes/day for five years ago $(n=30)$, and participants who had never smoked were considered in the control group $(n=31)$. The participant's inclusion criteria included; having no history of diabetes mellitus, hypertension, and coronary arterial disease, ideal weight, maintaining physical exercise with medium intensity three times a week. Laboratory analysts were blinded to smoking status during data collection and analysis.

\subsection{Collection and Isolation of PBMC}

Peripheral blood (5 mL/subject) was drawn by a heparinized venous puncture method at the forearm. PBMC isolated by density gradient centrifugation (catalogue\#07801/07811, LympoperpTM, Germany) with a density of $1.077 \mathrm{~g} / \mathrm{mL}$ ) as previously reported (Shi et al., 1998; Masuda et al., 2014; Beyth et al., 2015). Mononuclear cells were collected, and the remaining erythrocytes lysed. $\mathrm{CD}_{133^{+}}$and $\mathrm{CD} 117^{+}$marked cells were purified by FACS auto-separator, using fluorescence anti-human CD133 APC-conjugated antibody monoclonal mouse IgG2A clone \#170411 [FAB no.cat 11331A] and PE anti-human CD117/c-kit [Biolegend; no.cat. 323408].

\subsection{Flow cytometry}

Freshly isolated PBMC subjected to flow cytometry to detect surface antigen of EPC. The collected cell were resuspended with incubation buffer $(0.5 \mathrm{~g}$ bovine serum albumin in $100 \mathrm{ml} 1 \mathrm{X}$ PBS, stored at $4^{\circ} \mathrm{C}$ ). Aliquot made in $1 \times 106$ cells $/ 100 \mu \mathrm{l} /$ tube. Suspended were cells incubated in $10 \mu \mathrm{l} \mathrm{CD133}$ and $5 \mu \mathrm{l}$ CD117 by $100 \mu \mathrm{l}$ staining volume at room temperature for 20 minutes. The stained cells were washed with $\mathrm{PBS} / 1 \%$ BSA three times, resuspended in $0.5 \mathrm{ml} \mathrm{PBS} / 1 \% \mathrm{BSA} /$ propidium iodide (PI; Sigma). Flow cytometric profiles were obtained using FACS BD flow cytometer and Cell Quest software (Becton Dickinson Immunocytometry Systems, Mountain View, CA).

\subsection{SA- $\beta$ galactosidase assay}

Senescence-associated beta-galactosidase (SA- $\beta$ gal) activity was detected using Cell EventTM Senescense Green Flow Cytometry Assay Kit (Invitrogen; C10841) following the manufacturer's protocol (Thermo Fisher Scientific Inc.).

\subsection{FCM analysis}

The scatter diagram of each PBMC population in an individual is gated into a cell-sized population of lymphocytes, monocytes, and the other larger cells. The percentage (\%) of the marker positivity $\left(^{+}\right)$obtained from the EPCs population on each gate compared to the total cells in 3 gates.

\subsection{Ethical Clearance}

This experimental design has been fulfilled and approved by the Ethics Committee of Faculty of Medicine,
Brawijaya University, Malang, Indonesia, by registered number: 1206-KEP-UB/2019.

\subsection{Statistical Analysis}

The percentage of targeted cells in each group was analysed using SPPS v.23 in value \pm standard deviation. Student t-test was used to compare the means between groups. A p-value $\leq 0.05$ is statistically significant and indicates strong evidence against the null hypothesis.

\section{Result}

\subsection{Smoking induced the enrichment of circulating CD117+ cells}

Cell population that was positively selected from PBMC consists of $0.33 \%-3.25 \% \mathrm{CD} 117^{+}$cells and $0.15 \%-0.31 \% \mathrm{CD}_{113}{ }^{+}$cells (Figure 1 ), indicating the efficacy of the isolation method. The smoking group showed the enrichment of $\mathrm{CD} 117^{+}$cells compared to nonsmoker (10 fold in CD117 ${ }^{+}$cells; Table 1$)$. The average concentration of $\mathrm{CD} 117^{+}$cells in the current smoker group $(3.24 \% \pm 1.6)$ was significantly higher than in the nonsmokers' group $(0.33 \% \pm 0.07)(p<0.001)$.

3.2. The decrease of CD113+ cells in the current smoker group compared to the non-smoker group

The proportion of $\mathrm{CD} 113^{+}$cells of the current smoke group was $50 \%$ lower than the non-smoker group. Population of $\mathrm{CD} 133^{+}$cells in non-smokers $(0.31 \% \pm 0.3)$ was significantly higher than in smokers $(0.15 \% \pm 0.01)$ $(p<0.05)$ (Table 1$)$.

\subsection{Smoking increased the hematopoietic progenitor cell population compared to the non-smoker group}

Based on fluorescent cell sorting, large hematopoietic progenitor cells were proportionally found in PBMC of the current smoker group $(0.05 \% \pm 0.03)$ than the non-smoker group $(0.03 \% \pm 0.02)(p<0.05)$ (Table 1$)$.

\subsection{The SA- $\beta$-galactosidase-expressed Hematopoietic Progenitor Cells elevation in the smoker group}

In this study, the EPCs biological phenotype was evaluated by SA- $\beta$-galactosidase expression as a premature senescence hallmark. The senescence cells increased significantly in the current smoker group $(98.33 \% \pm 3.53)$. On the other hand, negative marked SA- $\beta$ galactosidase cell in non-smoker group was significantly higher $(55.51 \% \pm 34.96)$ than in the current smoker group $(p<0.001)$ (Table 1). Thus, it indicates that the premature senescence of EPCs increased due to the stress effect of smoking.

Table 1. Diversity of circulating progenitor cell populations in the smokers and non-smoker groups

\begin{tabular}{llll}
\hline \multirow{2}{*}{ Marker (\% gate) } & \multicolumn{3}{l}{ Circulating Progenitor Cell } \\
& $\begin{array}{l}\text { Smokers } \\
{[\mathrm{n}=30]}\end{array}$ & $\begin{array}{l}\text { Non-smokers } \\
{[\mathrm{n}=31]}\end{array}$ & t-test \\
\hline${\mathrm{CD} 133^{+}}^{+}$ & $0.15 \pm 0.01$ & $0.31 \pm 0.3$ & $0.011^{*}$ \\
$\mathrm{CD} 117^{+}$ & $3.24 \pm 1.63$ & $0.32 \pm 0.07$ & $0.000^{* *}$ \\
$\mathrm{CD}^{*} 33^{+} / \mathrm{CD} 117^{+}$ & $0.05 \pm 0.03$ & $0.03 \pm 0.02$ & $0.036^{*}$ \\
${\mathrm{CD} 133^{+} / \mathrm{CD} 117^{+} / \mathrm{SA}-\beta \text { gal. }}^{+}$ & $98.33 \pm 3.52$ & $55.51 \pm 5.10$ & $0.000^{* *}$ \\
${\mathrm{CD} 133^{+} / \mathrm{CD} 117^{+} \text {SA- } \beta \text { gal. }}^{-}$ & $1.67 \pm 3.53$ & $45.40 \pm 3.35$ & $0.000^{* *}$ \\
\hline
\end{tabular}

Data shown are the mean $\pm \mathrm{SD}$; Significant value $\mathrm{p}<0.05^{*}$, $\mathrm{p}<0.001^{* *}$ 

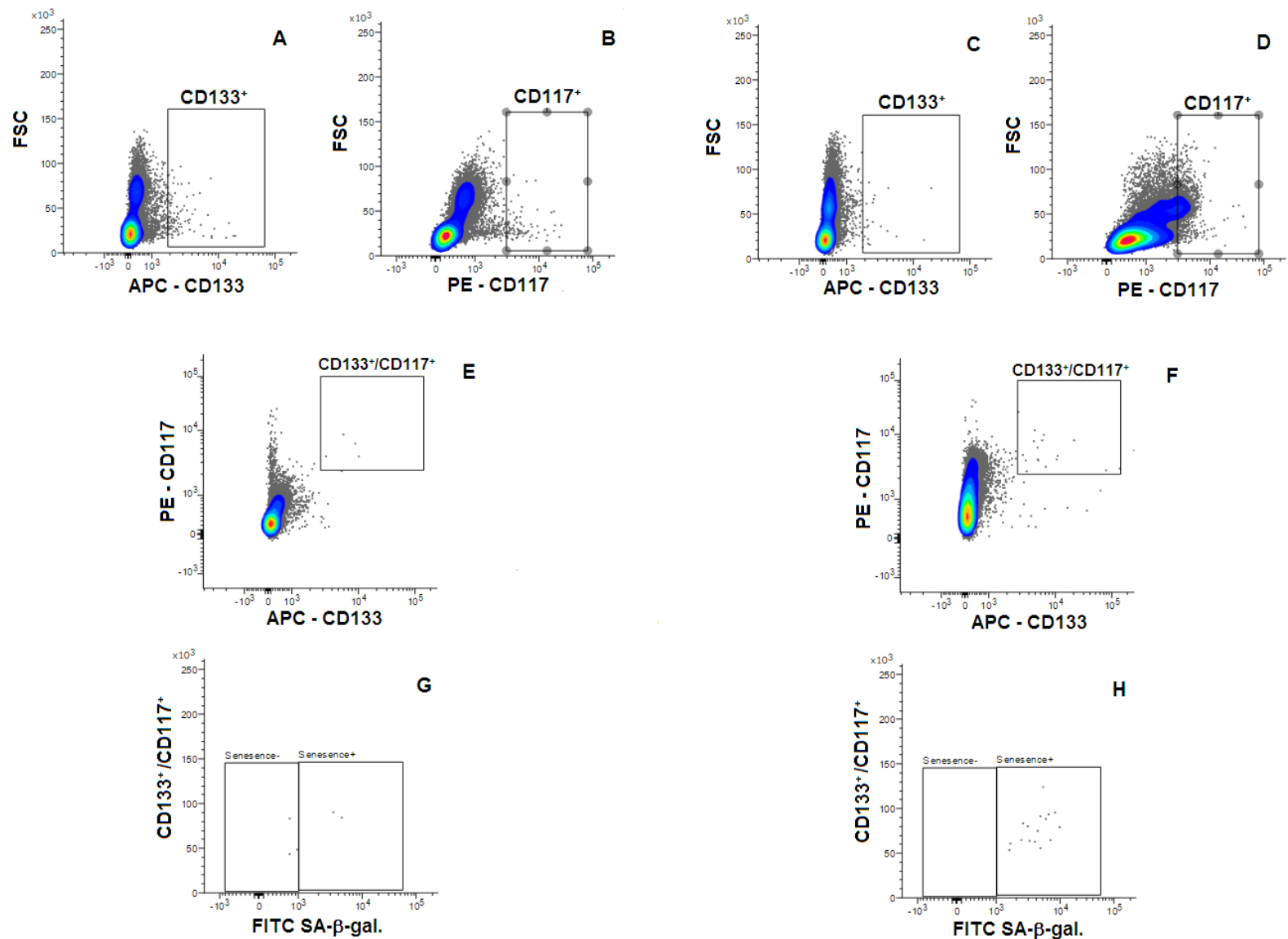

Figure 1. Cytometric analysis of cells that were positively CD133, CD117, and SA- $\beta$-galactosidase of each group. The investigated cell surface markers were hematopoietic progenitor cells (PE-CD117 ${ }^{+}$, APC-CD133 ${ }^{+}$). (A) CD133+ in non-smoker group; (B) CD117 ${ }^{+}$in non-

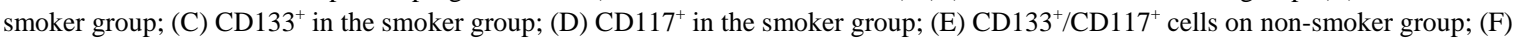
$\mathrm{CD} 133^{+} / \mathrm{CD} 117^{+}$cells on smoker group were higher than a non-smoker group; (G) senescence scatter plot gate which confirmed with SA- $\beta$ gal in non-smoker group; (H) senescence scatter plot visualization in the smoker group-representative analysis for one out of 61 PBMC samples.

\section{Discussion}

Reparative activity by EPCs has been declared in much research as a good advantage in both clinical approach and laboratory-based research. Still, it hasn't answered the remaining questions regarding the comprehensive framework of EPCs and their maturation in blood circulation. Based on their origin, bone marrow-derived EPCs biology is considered the source of EPCs and their differentiation through the vascular system. In this study, we used and compared different smoking habits that might exhibit different visualizing of biology EPCs.

The present study aimed to investigate EPCs viability through the premature senescence phenotype, confirmed by $\mathrm{CD}_{133^{+}} / \mathrm{CD} 117^{+}$. Our finding showed that the premature senescence of EPCs and increased $S A-\beta$ galactosidase-expressed hematopoietic progenitor cells population in the smoker group. These results suggest that the elevation of EPCs mobilization from bone marrow modulated by smoking to compensate responses due to the increase of the senescence cells.

Nicotine is the primary addictive component of tobacco. It is a highly toxic compound that exerts its effects on almost every organ and system in the body. Nicotine exposure in vitro induced cell death (about 50\%) in the MRC-5 cell line (Vajravelu et al., 2015). It also demonstrated that smoking also induces premature senescence in EPCs due to the effect of nicotine exposure. So, our result is in line with studies that investigate the cytotoxicity of tobacco compounds.

Analysis of aged stem cells in various tissues leads to common effectors and signalling pathways that contribute to stem cell dysfunction in response to toxic metabolites. Reactive oxygen species (ROS) that generated from electron 'leak' during mitochondrial oxidative phosphorylation plays fundamental roles in perturbed stem cell function leading to ageing (Takubo et al., 2013; Harris et al., 2013; Yu et al., 2013; Oh et al., 2014; Vlasceanu et al., 2018). In this study, the induction of actin filament reorganisation after a long time of nicotine exposure can be attributed to elevated cell senescence. Acrolein and other gas-phase oxidants in cigarette smoke remain stable in blood and thus are capable of acting directly on the vascular cells through impairs nitric oxide (NO)-mediated cell function (Bluhm et al., 1971; Barnova et al., 2005; Chung et al., 2005; Witschi et al., 2005; Mossman et al., 2006; Pervaiz et al., 2009; Lennartsson and Ronnstrand, 2012).

Smoking can trigger the ROS production enriched in both the gaseous and particulate components of smoking (Bluhm et al., 1971; Barnova et al., 2005; Kaplan et al., 2017). Alteration in ROS production due to cigarette smoking has a drastic effect on the host immunity through 
increasing the production of pro-inflammatory cytokines such as interleukin-8 (IL-8) and tumour necrosis factoralpha (TNF- $\alpha$ ) (Chung et al., 2005; Witschi et al., 2005). The data demonstrate the elevated circulation of circulating $\mathrm{CD}_{117^{+}}$cells in the smoker group, confirming the statement that expansion in $\mathrm{CD} 117^{+}$cells considered to the process of lineage diminished ability to self-renew, occurs in synergy with other cytokines and risk-factor (Mossman et al., 2006)

Surface protein CD117 plays a vital role in regulating survival, maintenance, self-renewal, and endothelial stem cell re-endothelization (Mossman et al., 2006). In addition, our study reports that oxidative stress-mediated by smoking-induced imbalance redox signalling for cellular senescence (Höhn et al., 2017). Also, our results showed that environmental stimuli could regulate stem cell function (Lennartsson and Ronnstrand, 2012; Ren et al., 2017). High premature senescence EPCs in the smoker group of this study impacted the availability of mature EPCs in circulation. The maturation of EPCs in blood circulation is the result of the differentiation of bone marrow-derived EPCs marked by current-EPCs that gradually disappeared and were replaced by endothelial cell markers. This EPCs senescence might be considered EPCs dysfunction, which is the cause of repair endothelial dysfunction failure due to oxidative stress (Tousoulis et al., 2008; Cruciani et al., 2020).

The oxidative stress from smoking influences the cardiovascular system in two ways; by directly delivering free radicals to the vascular system and consuming antioxidants that would generally be available to protect against endogenous free radicals occurring from the respiratory process. DNA damage in mitochondria induced from oxidative stress in smoking might influence the checkpoint phase and result in the cell cycle arrest (Ambrose and Barua,2004; Lennartsson and Ronnstrand, 2012; Ren et al., 2017). The latest report showed that EPCs stem cells exhibit a series of these age-related changes that could trigger cell dysfunction/death and, in turn, a progressive decline in regeneration capacity (Koyuncu et al., 2015)

\section{Conclusion}

This research finding showed that smoking increases of EPCs premature senescence. This knowledge is essential for improving senescent cells' identification and characterization in vivo and developing rational strategies to modulate the senescence program for therapeutic in high-risk CVD populations.

\section{Conflict OF Interest}

The authors declare no conflict of interest.

\section{Acknowledgements}

The study was supported by a research grant from the Ministry of Education and Culture, The Republic of Indonesia, through Brawijaya University.

\section{Authors Contributions}

KK, TAW, and WN designed this study and prepared the manuscript.
TAW, WN, INC, and KK collected and analysed the clinical data.

FYC and INC significantly revised the manuscript.

TAW and KK are responsible and accountable for the accuracy or integrity of the work.

\section{References}

Ambrose JA, and Barua RS. 2004. The pathophysiology of cigarette smoking and cardiovascular disease: an update. $\mathrm{J} \mathrm{Am}$ Coll Cardiol. 43(10): 1731-1737.

Barnoya J, and Glantz SA. 2005, Cardiovascular effect of secondhand smoke nearly as large as smoking, Circulation. 111: 2684-2698.

Beyth S, Mosheiff R, Safran O, Daskal A, and Liebergall M. 2015. Cigarette smoking is assosiated with a lower concentration of $\mathrm{CD}_{105^{+}}$Bone marrow progenitor cells. Bone Marrow Res. 2015: 914935.

Bluhm A, Weinstein J, and Sousa J. 1971. Free Radicals in Tobacco Smoke. Nature. 229: 500.

Chung KF. 2005. Inflammatory mediators in chronic obstructive pulmonary disease. Curr Drug Targets. 4(6): 619-625.

Cruciani S, Garroni G, Ginesu GC, Fadda A, Ventura C, and Maioli M. 2020. Unravelling Cellular Mechanisms of Stem Cell Senescence: An Aid from Natural Bioactive Molecules. Biology (Basel). 9(3): 57. Published 2020 Mar 20

Gargett CE, Schwab KE, Zillwood RM, Nguyen HP, and Wu D. 2009. Isolation and culture of epithelial progenitors and mesenchymal stem cells from human endometrium. Biol Reprod. 80(6): 1136-1145.

Greenberg JM, Carballosa CM, and Cheung HS. 2017. Concise Review: The Deleterious Effects of Cigarette Smoking and Nicotine Usage and Mesenchymal Stem Cell Function and Implications for Cell-Based Therapies. Stem Cells Transl Med. 6(9): 1815-1821.

Harris JM, Esain V, Frechette GM, Harris LJ, Cox AG, Cortes M, Garnaas MK, Carroll KJ, Cutting CC, Khan T, Elks PM, Renshaw SA, Dickinson BC, Chang CJ, Murphy MP, Paw BH, Vander Heiden MG, Goessling W, and North TE. 2013. Glucose metabolism impacts the spatiotemporal onset and magnitude of HSC induction in vivo. Blood. 121(13): 2483-2493.

Höhn A, Weber D, Jung T, Ott C, Hugo M, Kochlik B, Kehm R, König J, Grune T, and Castro JP. 2017. Happily (n)ever after: Aging in the context of oxidative stress, proteostasis loss and cellular senescence. Redox Biol. 11: 482-501.

Huertas A, Testa U, Riccioni R, Petrucci E, Riti V, Savi D, Serra P, Bonsignore MR, and Palange P. 2010. Bone marrow-derived progenitors are greatly reduced in patients with severe COPD and low-BMI. Respir Physiol Neurobiol. 170: 23-31.

Hur J, Yoon CH, Kim HS, Choi J, Kang H, Hwang KK, Oh B, Lee M, and Park YB. 2004. Characterization of Two Types of Endothelial Progenitor Cells and Their Different Contributions to Neovasculogenesis. Arterioscler Thromb Vasc Biol. 24: 288-293.

Kaplan A, Abidi E, Ghali R, Booz GW, Kobeissy F, and Zouein FA. 2017. Functional, Cellular, and Molecular Remodeling of the Heart under Influence of Oxidative Cigarette Tobacco Smoke. Oxid Med Cell Longev. 2017: 3759186.

Koyuncu S, Irmak D, Saez I, and Vilchez D. 2015. Defining the General Principles of Stem Cell Aging: Lessons from Organismal Models. Curr Stem Cell Rep. 1: 162-9.

Kumboyono K, Hamid AYS, Sahar J, and Bardosono S. 2020. Community response to the initiation of smoking in Indonesian early adolescents: a qualitative study. Int J Adolesc Youth. 25(1): 210-220, 
Kurz DJ, Decary S, Hong Y, and Erusalimsky JD. 2000. Senescence-associated (beta)-galactosidase reflects an increase in lysosomal mass during replicative ageing of human endothelial cells. J Cell Sci.113 ( Pt 20): 3613-3622.

Lee BY, Han JA, Im JS, Morrone A, Johung K, Goodwin EC, Kleijer WJ, DiMaio D, and Hwang ES. 2006. Senescenceassociated beta-galactosidase is lysosomal beta-galactosidase. Aging Cell. 5(2): 187-195.

Lennartsson J, and Ronnstrand L. 2012. Stem Cell Factor Receptor/c-Kit: From Basic Science to Clinical Implications. Physiol Rev. 92: 1619-1649.

Masuda H, Tanaka R, Fujimura S, Ishikawa M, Akimaru H, Shizuno T, Sato A, Okada Y, Iida Y, Itoh J, Itoh Y, Kamiguchi H, Kawamoto A, and Asahara T. 2014. Vasculogenic conditioning of peripheral blood mononuclear cells promotes endothelial progenitor cell expansion and phenotype transition of antiinflammatory macrophage and $\mathrm{T}$ lymphocyte to cells with regenerative potential. J Am Heart Assoc. 3(3): e000743.

Mossman BT, Lounsbury KM, and Reddy SP. 2006. Oxidants and signaling by mitogen-activated protein kinases in lung epithelium. Am J Respir Cell Mol Biol. 34(6): 666-669.

Oh J, Lee YD, and Wagers AJ. 2014. Stem cell aging: mechanisms, regulators and therapeutic opportunities. Nat Med. 20(8): 870-880.

Pervaiz S, Taneja R, and Ghaffari S. 2009. Oxidative stress regulation of stem and progenitor cells. Antioxid Redox Signal.11: 2777-2789.

Rafacho BP, Azevedo PS, Polegato BF, Fernandes AAH, Bertoline MA, Fernandes DC, Chiuso-Minicucci F, Roscani MG, dos Santos PP, Matsubara LS, Matsubara BB, Laurindo FRM, Paiva SAR, Zornoff LAM, and Minicucci MF. 2011.Tobacco smoke induces ventricular remodeling associated with an increase in NADPH oxidase activity. Cell Physiol Biochem. 27(3-4): $305-$ 312.

Ren R, Ocampo A, Liu GH, and Izpisua Belmonte JC. 2017. Regulation of Stem Cell Aging by Metabolism and Epigenetics. Cell Metab. 26(3): 460-474.

Shi Q, Rafii S, Wu MH, Wijelath ES, Yu C, Ishida A, Fujita Y, Kothari S, Mohle R,Sauvage LR, Moore MA, Storb RF, and Hammond WP. 1998. Evidence for circulating bone marrowderived endothelial cells. Blood. 92: 362-367.

Tagawa S, Nakanishi C, Masayuki M, Yoshimuta T, Shimojima YS, Yokawa M, Kawashiri J, Yamagishi M, and Hayashi K. 2015. Determination of Early and Late Endothelial Progenitor Cells in Peripheral Circulation and Their Clinical Association with Coronary Artery Disease. Int J Vasc Med. 674213.
Takubo K, Nagamatsu G, Kobayashi CI, Nakamura-Ishizu A, Kobayashi H, Ikeda E, Goda N, Rahimi Y, Johnson RS, Soga T, Hirao A, Suematsu M, and Suda T. 2013. Regulation of glycolysis by Pdk functions as a metabolic checkpoint for cell cycle quiescence in hematopoietic stem cells. Cell Stem Cell.12(1): 4961.

Tousoulis D, Andreou I, Antoniades C, Tentolouris C, and Stefanadis C.2008. Role of inflammation and oxidative stress in endothelial progenitor cell function and mobilization: Therapeutic implications for cardiovascular diseases. Atherosclerosis. 201(2): 236-47.

Vajravelu BN, Hong KU, Al-Maqtari T, Cao P, Keith MCL, Wysoczynski M, Zhao J, Moore JB 4th, and Bolli R. 2015. C-Kit Promotes Growth and Migration of Human Cardiac Progenitor Cells via the PI3K-AKT and MEK-ERK Pathways. PLoS ONE. 10(10):

Vlasceanu AM, Baconi DL, Galateanu B, Miriana S, and Cristian B. 2018. Comparative cytotoxicity study of nicotine and cotinine on MRC-5 cell line. Mind Med Sci. 5(1): 117-122,

Witschi H. 2005. Carcinogenic activity of cigarette smoke gas phase and its modulation by beta-carotene and $\mathrm{N}$-acetylcysteine. Toxicol. Sci.. 84:1:81-7.

Yao H, Edirisinghe I, Yang SR, Rajendrasozhan S, Kode A, Caito S, Adenuga D, and Rahman I. 2008. Genetic ablation of NADPH oxidase enhances susceptibility to cigarette smoke-induced lung inflammation and emphysema in mice. Am J Pathol.172(5): 12221237.

Young AR, Narita M, Ferreira M, Kirschner K, Sadaie M, Darot JF, Tavaré S, Arakawa S, Shimizu S, Watt FM, and Narita M. 2009. Autophagy mediates the mitotic senescence transition. Genes Dev. 23(7): 798-803.

Yu WM, Liu X, Shen J, Jovanovic O, Pohl EE, Gerson SL, Finkel T, Broxmeyer HE, and Qu CK. 2013. Metabolic regulation by the mitochondrial phosphatase PTPMT1 is required for hematopoietic stem cell differentiation. Cell Stem Cell. 12(1): 62-74.

Zhang M, Rehman J, and Malik AB. 2014. Endothelial progenitor cell and vascular repair, Curr Opin Hematol. 21(3): 224-228.

Zhao J, Mitrofan CG, Appleby SL, Morrell NW, and Lever AML. 2016. Disrupted Endothelial Cell Layer and Exposed Extracellular Matrix Proteins Promote Capture of Late Outgrowth Endothelial Progenitor Cells. Stem Cells Int. Volume, 2016: 1406304. 